\title{
A TRANSFORMAÇÃO SOCIAL DE UMA FERRAMENTA ESTRATÉGICA EM UMA ORGANIZAÇÃO FAMILIAR BRASILEIRA ${ }^{1}$
}

\author{
Eros Renato Silva Cardoso² \\ Alfredo Rodrigues Leite da Silva ${ }^{3}$
}

http://dx.doi.org/10.1590/1413-2311.153.56537

\begin{abstract}
RESUMO
O objetivo deste artigo é compreender o fenômeno de transformação de um software, com potencial para ser uma ferramenta estratégica, pelas construções sociais dos atores inseridos em uma organização familiar brasileira. Defende-se que as ferramentas estratégicas podem ser transformadas pelas construções sociais de seus usuários articuladas nos contextos em que estão inseridos. Para compreender o fenômeno dessas transformações nas ferramentas estratégicas, discute-se a temática da construção social nas organizações, reconhecendo as implicações das especificidades sociais das organizações familiares. Esta pesquisa trouxe uma abordagem fenomenológica do mundo social de Schütz. O lócus do estudo foi uma organização familiar do setor de vendas de equipamentos comerciais no estado do Espírito Santo - Brasil. A coleta de dados se deu a partir de dezessete entrevistas semiestruturadas, observação participante e pesquisa documental. A análise dos dados foi inspirada no método fenomenológico. A justificativa deste trabalho está em contribuir para preencher lacunas de pesquisa sobre a transformação das ferramentas estratégicas no "fazer estratégia" em uma ótica socialmente construída, por meio de articulações teóricas e empíricas. Como resultados, questões como o despreparo, o feeling, as redes de motivos e interesses, as imposições, as heranças do contexto, as tentativas (d)e manutenção de práticas, a experiência de vida do indivíduo e interesses organizacionais, entre outras, evidenciaram que as transformações da ferramenta foram causadas pelas redes de motivos e interesses, tanto institucionais quanto específicos dos atores sociais, imersos em construções sociais no contexto.
\end{abstract}

Palavras-chave: Construção Social. Ferramentas Estratégicas. Fenomenologia. Organizações Familiares.

\section{THE SOCIAL TRANSFORMATION OF A POTENTIALY STRAEGIC TOOL IN A BRAZILIAN FAMILY ORGANIZATION}

\begin{abstract}
The purpose of this article is to understand the phenomenon of transformation of a software with the potential to be a strategic tool, by the social constructions of actors in a family

\footnotetext{
${ }^{1}$ Recebido em 18/06/2015; aprovado em 21/09/2017.

${ }^{2}$ Universidade Federal do Espírito Santo - eros_renato@ hotmail.com.

${ }^{3}$ Universidade Federal do Espírito Santo - alfredoufes@ gmail.com.
} 
organization. It is argued that strategic tools can be transformed by the social constructs of their articulated users in the contexts in which they are inserted. To understand the phenomenon of these changes in the strategic tools, discusses the theme of social construction in organizations, recognizing the implications of social specificities of family organizations. This research brought a phenomenological approach by the social world of Schütz. The locus of the study was a family organization of sales of commercial equipment sector in the state of Espírito Santo - Brazil. Data collection occurred from seventeen semi-structured interviews, participant observation and document research. Data analysis was inspired on the phenomenological method. The justification for this work is to contribute to filling research gaps about the transformation of strategic tools into "strategy making" in a socially constructed perspective, through theoretical and empirical articulations. As a result, issues such as the lack of preparation, the feeling, the reasons and interests' networks, levies context of the legacies, attempts and maintenance of practices, the individual's life experience and organizational interests, among others, showed the transformation in tool were caused by the networks of motives and interests, both institutional and specific social actors, immersed in social constructions in context.

Key words: Social Constructions. Strategic Tools. Phenomenology. Family Business.

\section{LA TRANSFORMACIÓN SOCIAL DE UNA HERRAMIENTA ESTRATÉGICA EN UNA ORGANIZACIÓN FAMILIAR BRASILEÑA}

\section{RESUMEN}

El propósito de este artículo es entender el fenómeno de la transformación de un software con el potencial de ser una herramienta estratégica, por las construcciones sociales de los agentes de una organización familiar. Se argumenta que las herramientas estratégicas pueden ser transformadas por las construcciones sociales de sus usuarios articulados en los contextos en los que están inseridos. Para entender el fenómeno de estos cambios en las herramientas estratégicas, discute el tema de la construcción social en las organizaciones, reconociendo las implicaciones de las especificidades sociales de las organizaciones familiares Esta investigación trajo un enfoque fenomenológico del mundo social de Schütz. El locus del estudio fue una organización familiar de las ventas de equipos del sector comercial en el estado de Espírito Santo - Brazil. La recolección de datos ocurrió a partir de diecisiete entrevistas semi-estructuradas, observación participante y de investigación de documentos. Análisis de los datos se inspirado en el método fenomenológico. La justificación de este trabajo está en contribuir a llenar lagunas de investigación sobre la transformación de las herramientas estratégicas en el "hacer estrategia" en una óptica socialmente construida, a través de articulaciones teóricas y empíricas. Como resultado, los problemas como la falta de preparación, el feeling, las redes de razones e intereses, imposiciones; los legados del contexto, intentos de (y) mantenimiento de las prácticas, la experiencia de vida del individuo y de los intereses de la organización, entre otros, mostraron que a transformación de la herramienta fueron causados las las redes de los motivos e intereses, tanto de los actores sociales e institucionales específicos, inmerso en las construcciones sociales de contexto.

Palabras-clave: Construcción Social. Herramientas Estratégicas. Fenomenología; Empresa Familiar. 


\section{INTRODUÇÃO}

Ao investigar as ferramentas estratégicas podemos defini-las como conceitos e técnicas, que podem ter diversas formas (tangíveis ou abstratas) que ajudam na tomada de decisão (GUNN; WILLIAMS, 2007; HODARY, 2009). A despeito dessa diversidade de formas, neste artigo defende-se que há um ponto em comum entre elas: ao serem articuladas no contexto organizacional elas são transformadas socialmente. Isso ocorre porque o uso das ferramentas estratégicas, assim como a estratégia, devem ser tratadas como algo que as pessoas fazem.

Os estudos de Kaplan e Jarzabkowski (2006, p. 39) revelam que as ferramentas estratégicas "são muito mais ambíguas do que seus desenvolvedores previram”, o que por sua vez possibilita o "fazer mudanças". Jarzabkowski e Giulietti (2007) apontam para o "uso" das ferramentas influenciado por diversos fatores que deságuam na explicação do seu uso instrumental e o simbólico.

Com base nesse entendimento, defende-se a necessidade de desenvolver estudos que tratem das transformações das ferramentas estratégicas considerando seus contextos de aplicação, aos quais são adaptadas por seus usuários (JARRATT; STILES, 2010). Essas adaptações envolvem simbolismos, motivações e interesses por trás dos usos das ferramentas na interação com o contexto organizacional, um processo de transformação social, ainda pouco estudado (GUNN; WILLIAMS, 2007; SPEE; JARZABKOWSKI, 2009; BELMONDO; SARGIS-ROUSSEL, 2015).

Para preencher essa lacuna neste artigo acrescenta-se a essa discussão um aspecto relacionado com as transformações potenciais de uma ferramenta: o contexto da organização familiar (FISCHER, 2000). Nesse sentido parte-se da discussão do seguinte problema de pesquisa: como um software com potencial para ser uma ferramenta estratégica é transformado pelas construções sociais dos atores sociais inseridos em uma organização familiar brasileira?

A partir desse problema este artigo se voltou para o seguinte objetivo: compreender o fenômeno de transformação de um software, com potencial para ser uma ferramenta estratégica, pelas construções sociais dos atores inseridos em uma organização familiar brasileira. Para a compreensão desse fenômeno adotou-se a pesquisa de abordagem qualitativa. A coleta de dados se baseou em dezessete entrevistas, observação participante e pesquisa documental. A análise dos dados teve como inspiração a fenomenologia de Schütz 
(1967). Essa escolha foi realizada pelo interesse em buscar as experiências do indivíduo socialmente construído - com a ferramenta em questão. A operacionalização da abordagem fenomenológica neste artigo aproveita as propostas de Sanders (1982), alinhadas para o contexto organizacional (MACEDO; BOAVA; ANTONIALLI, 2012).

O locus de pesquisa escolhido é uma organização familiar que atua em vendas de equipamentos comerciais no centro e norte do estado do Espírito Santo, Brasil. Essa organização iniciou a implantação de um software com propósitos operacionais e estratégicos, integrando suas diversas lojas. Os usos e transformações sociais dessa ferramenta embasam os confrontos teóricos empíricos realizados neste artigo.

A motivação para a execução desta pesquisa foi contribuir para preencher lacunas de pesquisa sobre a transformação das ferramentas estratégicas no "fazer estratégia" em uma ótica socialmente construída, por meio de articulações teóricas e empíricas. Essas últimas com base nas práticas de gerentes ("gerentes de loja" que agrupam conjuntos de vendedores), gestores (responsáveis pela compra, análise de estoque e precificação dos seus grupos de produtos), diretores e sócios da organização pesquisada com foco em um "fazer estratégia" socialmente construído (WATSON, 2003, BERGER; LUCKMANN, 1985).

Para desenvolver essa discussão o artigo está organizado da seguinte maneira: inicialmente, discute-se a construção social da realidade nas organizações para, então, tratar das ferramentas estratégicas e suas transformações nas construções sociais no contexto organizacional; em seguida, trata-se das especificidades do contexto de uma organização familiar e suas implicações para as transformações sociais em questão; para confrontar empiricamente as contribuições teóricas articuladas é apresentada a metodologia utilizada na coleta e análise de dados empíricos, seguida da análise dos dados e das considerações finais.

\section{A CONSTRUÇÃO SOCIAL DA REALIDADE}

A concepção da chamada Construção Social da Realidade baseia a discussão desenvolvida neste artigo e tem o trabalho de Berger e Luckmann (1985) como seminal (BURR, 2003; GILL, 2014), e as obras de Gergen (1999) e Burr (2003) como desenvolvimentos mais recentes sobre a realidade socialmente construída.

Em termos influências sobre a abordagem da Construção Social da Realidade, Schwandt (2000) aponta as convergências e divergências entre o Interpretacionismo, a Hermenêutica e a Fenomenologia Sociológica, sendo que é possível perceber a contribuição 
de cada um destes posicionamentos para construção social. As características em comum das três abordagens são:

(a) todas veem a atividade humana como significante; (b) elas evidenciam o comprometimento ético em forma de respeito e fidelidade para a vida no mundo; e (c) [...] enfatizam o desejo de contribuir para a subjetividade humana (i.e, intenção) do conhecimento sem por outro lado comprometer a objetividade do conhecimento (SCHWANDT, 2000, p. 193).

O reflexo dessas características na Construção Social (CS) é a atividade tratada como significante, sendo por meio dela a identificação da realidade socialmente construída, o "entendimento" do fenômeno de uma maneira objetivada pela construção social, considerada como capaz de reificar e objetivar a realidade.

A apreensão deste fenômeno está ligada à linguagem, ao conhecimento e ao significado (SCHWANDT, 2000). É a partir da linguagem que o conhecimento e os significados são repassados nas relações sociais que geram as experiências de mundo (ANDREWS, 2012). A linguagem tem uma relação com os significados das palavras, com um objeto/algo a que possa ser referido e com uma estrutura. Entender a construção social é compreender como as práticas sociais buscam estratégias que são utilizadas dentro de certas articulações do discurso (SCHWANDT, 2000).

O homem vive, cria sua biografia (história), gera uma sociedade (quando em relacionamento com outro) e é influenciado por essa sociedade (BERGER; LUCKMANN, 1985). As ações sociais geram conhecimento quando possuem certa frequência e um padrão. Elas possibilitam aos indivíduos acessarem hábitos frequentemente padronizados, em sentido de um depósito histórico de conhecimentos e experiências, evitando a criação das mesmas ações, deixando os indivíduos se voltarem para a inovação, gerando novos conhecimentos, e a partir de sua frequência, produz um ciclo (ANDREWS, 2012).

Nesse processo a "vida cotidiana apresenta-se como uma realidade interpretada pelos homens e subjetivamente dotada de sentido para eles, na medida em que forma um mundo coerente" (BERGER; LUCKMANN, 1985, p. 35). Essa formação de coerência é a própria formação do senso comum, que não é comum a todos, mas apenas ao grupo que o construiu socialmente como elemento de uma realidade distinta.

Gergen (1999) dá um exemplo sobre a realidade dos indivíduos, descrevendo uma situação em que, se pessoas com formações diferentes olhassem para uma mesma paisagem através de uma janela, a interpretariam distintamente. A visão de um botânico seria voltada para a flora, a de um paisagista seria para as questões do terreno e a possibilidade de 
aperfeiçoar a vista da janela; e podemos acrescentar ainda, a visão de um fazendeiro que poderia olhar para a paisagem enquanto área útil para criação de animais. Todas estas visões são "válidas", reais para cada um daqueles indivíduos, porém bastante divergentes, são realidades próprias, desenvolvidas a partir da história de vida, conjunto social, de cada um deles.

A forma indicada por Berger e Luckmann (1985) para investigar a vida cotidiana é a sua experiência subjetiva, isto é a experiência do sujeito em contato com a formação da sua realidade. A formação da realidade nos termos da construção social se dá como objetivada, o que permite entender que ela é anterior à formação de conhecimento pelo indivíduo, mas isso não significa que ela seja natural, significa que ela é construída previamente como objetivada.

A linguagem na vida cotidiana fornece "continuamente as necessárias objetivações e determina a ordem em que estas adquirem sentido e na qual a vida cotidiana ganha significado" (BERGER; LUCKMANN, 1985, p. 38). Isto nos leva à conclusão de que a linguagem é um pré-requisito para o pensamento (BURR, 2003), um pré-requisito para o conhecimento da realidade.

Os vocabulários articulados a partir da linguagem não emergem da natureza, e sim das práticas diárias, que no caso de um grupo de profissionais de uma área, por exemplo, cunham termos para explicar o que eles veem, como "formas de descrição e explicação particular das tradições da prática" (GERGEN, 1999, p. 14). Dessa forma, temos a linguagem como uma forma de ação social com um relacionamento direto com a vida cotidiana, pois, como já se discutiu, é através dela que se dará o conhecimento da realidade social.

Para Berger e Luckmann (1985), a forma básica de linguagem para o compartilhamento de conhecimento é a interação entre duas pessoas em uma situação face a face, quando uma série de informações pode ser transmitida pelo comportamento, postura, que levam a formulações de tipificações.

O sentido ou significado de uma palavra, ação, som ou outra forma de comunicação na interação pode nos levar a alcançar, não só o sentido direto embutido na ação social, podem também possibilitar acessar e indagar quanto a subjetividade de um sujeito. Berger e Luckmann (1985) ilustram essa questão com o exemplo de uma faca arremessada contra uma pessoa, a faca passa a representar uma fonte de ameaça e possibilita a leitura de um problema do arremessador contra o indivíduo. Isso pode representar raiva ou desgosto, gerado por alguma contenda anterior, sendo então que a faca objetiva estes sentimentos, o que por sua vez possibilita a leitura da subjetividade do sujeito. Assim, a faca arremessada, torna-se uma 
forma de linguagem que envolve o processo de construção social da realidade entre os envolvidos e ao contar o acontecido a outras pessoas, essas também passarão a ver na faca a objetivação da raiva do arremessador. "Noutras palavras, a faca em minha parede tornou-se um constituinte objetivamente acessível da realidade que partilho com meu adversário e com outros homens" (BERGER; LUCKMANN, 1985, p. 54).

Assim, as pessoas que não estão envolvidas, que não sabem do ocorrido, não verão nesta faca tal objetivação. Esse argumento acrescenta que embora a faca em questão possua este significado, facas em geral como objetos reais, físicos, só serão reconhecidas como armas pelos indivíduos que souberem o que significa ser uma arma, e aqui se percebe que o foco da construção social não é entender a faca como um metal, mas como um elemento das objetivações e subjetivações que surgem; o foco está em entender como esse fenômeno ocorre a partir da interação social e como o conhecimento é construído pelo relacionamento. Em termos do objetivo deste artigo pode-se dizer que a faca foi transformada socialmente, assim como pode ocorrer com uma ferramenta estratégica. E as facas, assim como as ferramentas estratégicas, fazem parte das ações sociais compartilhadas por indivíduos e, com o passar do tempo, elas darão origem às instituições controladoras da vida social, por meio da institucionalização que prossegue no tempo (BERGER; LUCKMANN, 1985). Em virtude da institucionalização a cultura permite o compartilhamento de um mundo específico permeado por objetividades (ALEXANDRE, 2004).

As instituições a que Berger e Luckmann (1985) se referem são, por exemplo, as relacionadas com a estrutura da família, e o casamento, que são dotadas de potencial para o controle social e podemos complementar que se pode trazer a mesma forma de análise para as instituições organizacionais. Em outras palavras, é possível considerar, extrapolando o sentido de instituição da sociedade, as organizações como sociedades instituídas. Portanto, assume-se aqui que as organizações são complexas, permeadas por múltiplos contextos e construções sociais em seu cotidiano, e que ao se alterar um aspecto nas organizações, possivelmente terse-á mudanças em outros aspectos organizacionais.

Esse entendimento leva ao foco deste trabalho que são as transformações sociais nas ferramentas estratégicas. Essas são reconhecidas como formas de se alterar algo na organização, sendo que o olhar a ser dado é a partir da prática social articulada nas construções sociais (BERGER; LUCKMANN, 1985). Esse entendimento tem o potencial de contribuir para a discussão sobre as transformações de ferramentas estratégicas. 


\section{FERRAMENTAS ESTRATÉGICAS E SUAS TRANSFORMAÇÕES PELA CONSTRUÇÃO SOCIAL}

Em uma concepção instrumental, as ferramentas estratégicas são consideradas como um conjunto de conceitos e técnicas que dão assistência à tomada de decisão (GUNN; WILLIAMS, 2007). Hodary (2009, p. 20) complementa essa questão ao descrever que ferramentas estratégicas "podem ser físicas, processuais ou conceituais [...] entre outros, computadores, post-it notes, técnicas de gestão por projetos e modelos analíticos".

Dentro da abordagem aqui defendida essas concepções devem ser complementas pelas contribuições sobre a construção social da realidade já discutidas. Com base nelas pode-se afirmar que as ferramentas estratégicas são artefatos simbólicos, inseridos em construções sociais, o que permite articular um conceito que contribua com o objetivo proposto neste artigo: as ferramentas estratégicas são tecnologias conceituais, físicas ou processuais que dão suporte ao processo decisório ligado à estratégia organizacional, ao mesmo tempo em que carregam simbolismos e se relacionam com as construções sociais dos grupos envolvidos direta ou indiretamente com essas ferramentas.

Por exemplo, um software só será tratado como uma ferramenta estratégica quando além de organizar, demonstrar dados e informações possa dar suporte ao processo decisório ligado à estratégia organizacional. Se suas informações tiverem um uso meramente operacional essa ferramenta não será estratégica. Por outro lado, cabe destacar que uma ferramenta articulada no cotidiano de uma organização, seja ela estratégica ou não, vai carregar simbolismos e se relacionar com construções sociais. Mas as ferramentas estratégicas, foco deste artigo, têm o propósito instrumental de viabilizar uma suposta estratégia a ser definida para toda a organização. Contudo na prática, cada ator social a usa com modos, interpretações e propósitos específicos (BELMONDO; SARGIS-ROUSSEL, 2015). É justamente esse contraste potencial, entre o deliberado e o praticado, que interessa para a discussão aqui proposta.

Nesse sentido, segundo Belmondo e Sargis-Roussel (2015), os artefatos estratégicos são capazes de tornar explícitos os desacordos, os significados e as intenções. Isto é, "em um macro-nível uma prática é uma forma institucionalizada de fazer algo. No micro-nível é uma forma de fazer algo por uma razão" (BELMONDO; SARGIS-ROUSSEL, 2015, p. 92). Neste artigo, o artefato em questão é a ferramenta estratégica, inserida em múltiplas construções sociais. 
Em virtude dessas múltiplas construções, por trás do "porquê" e "como usam" as ferramentas estratégicas existem redes de motivações e interesses, muito mais subjetivas do que objetivas. Justamente para compreender essas articulações é que se optou por tratar dessas transformações a partir da prática social (BERGER; LUCKMANN, 1985).

$\mathrm{O}$ entendimento de que os artefatos estratégicos podem alterar algo nas organizações exige reconhecer a ação humana (BERGER; LUCKMANN, 1985), permeada pelo contexto social, que ao entrar em contato com novos objetos, experiências, ou outros contextos, pode transformar os elementos que compõem o contexto. Isto é, se mudarmos a composição, ou os objetos com os quais os indivíduos se relacionam, por exemplo, ao mudar a estratégia ou mais precisamente, ao escolher e usar uma ferramenta estratégica, a realidade organizacional poderá ser influenciada e possivelmente transformada. Em outras palavras, as "ferramentas estratégicas são engajadas por diferentes atores na mediação do fazer estratégia” (KAPLAN; JARZABKOWSKI, 2006, p. 4) com o potencial de influenciar seu contexto.

Ao investigar esse fazer estratégia e o uso de ferramentas estratégicas a partir dele, este artigo assume que ao influenciar o contexto, a ferramenta também é influencia por ele, em um processo no qual se transforma. Nesse sentido, Mussi e Zwicker (2012, p. 419) apontam que as interpretações construídas socialmente, influenciam as ferramentas, pois em seu estudo elas foram "fortemente afetadas pelo que acreditam, conhecem e esperam desse sistema".

Esse aspecto exige reconhecer o contexto ao estudar a transformação das ferramentas estratégicas. Entretanto, segundo Jarratt e Stiles (2010), a aplicação de ferramentas estratégicas tem sido estudada fora de seus contextos e consequentemente, a forma pela qual as ferramentas estratégicas são adaptadas e transformadas, ainda é pouco compreendida (GUNN; WILLIAMS, 2007; SPEE; JARZABKOWSKI, 2009; BELMONDO; SARGISROUSSEL, 2015). Este artigo contribui para preencher esta lacuna ao tratar de uma ferramenta estratégica em um "fazer estratégia” socialmente construído (WATSON, 2003, BERGER; LUCKMANN, 1985).

A investigação empírica parte do entendimento de que um software possui o potencial para ser uma ferramenta estratégica, assim como o são as ferramentas "cognitivas" estratégicas, por exemplo, as "cinco forças" (JARZABKOWSKI; KAPLAN, 2015, p. 537). Ao colocar um software nessa condição o estudo aqui proposto envolve aspectos como a discussão sobre "quem usa" (JARZABKOWSKI et al., 2013) a ferramenta e o uso dessa ferramenta na busca por aumentar a eficiência (SANCHIS; CAMPOS; MOHEDANO, 2013). 
No Brasil, são poucos os estudos empíricos sobre "fazer estratégia" (TURETA; LIMA, 2011) e ao considerarmos o foco adicional no uso das ferramentas, ao investigar esse fazer, o espaço para contribuições é ainda maior. Um esforço que se insere dentro de um movimento acadêmico contemporâneo para ampliar estudos com base na teoria da prática (VOGEL, 2012; BISPO, 2013). A discussão das práticas é a base da compreensão do "fazer estratégia" envolvendo a transformação da ferramenta aqui investigada.

Assume-se que as ferramentas estratégicas são transformadas quando são usadas no contexto organizacional. Com base no que foi discutido até aqui, isso ocorre, pois, além delas se relacionarem com as construções sociais dos membros organizacionais em geral, a escolha de uma ferramenta estratégica é permeada por uma rede de influências contextuais. Tanto a construção social, quanto essas influências contextuais subjetivas podem levar as ferramentas a serem utilizadas não para cumprir seu objetivo original, mas para outras utilidades, sendo transformadas para isso, tais como se alinhar a questões pessoais ou políticas, por exemplo. No caso da discussão proposta neste artigo, entre outras influências contextuais, se dá especial atenção à discussão das influências referentes ao contexto de uma organização familiar, com suas características específicas.

\section{O CONTEXTO DA ORGANIZAÇÃO FAMILIAR}

A ação humana deve ser analisada tendo como base o seu contexto, no caso das organizações, um tipo que se diferencia das outras são as organizações familiares, marcada por ser permeada pelo contexto familiar. Portanto, nelas, além do contexto organizacional se deve considerar o contexto da família na organização. Segundo Silva Junior, Martins Silva e Silva (2013), não há consenso na literatura sobre uma definição do que seria uma empresa familiar. Santiago (2011) explica que a dificuldade para se chegar a uma definição consensual começa com a própria definição de "família", que pode ser extremamente variável e complexa, levando estes aspectos para a definição de "empresa familiar".

Contudo, parece existir um consenso de que "o que faz das organizações familiares únicas é a interação da família com a gestão empresarial e com o regime de propriedade" (SILVA JUNIOR; MARTINS SILVA; SILVA, 2013, p. 240). Esta interação faz com que as organizações familiares estejam justamente no limite de contato entre o mercado e a família. Por conta dessa diferenciação as empresas familiares possuem características diferentes, únicas, cuja composição do seu contexto, da sua gestão e do seu planejamento estratégico é 
influenciada pela família, assim como tem o potencial de influenciar a família.

Sobre a relação entre a família e a organização, Ward (1988) discute que o planejamento estratégico em empresas familiares se difere do que ocorre nas outras empresas, pois deve levar em conta no planejamento os problemas familiares. Isso ocorre, pois faz parte do crescimento das empresas familiares a articulação entre a família e a organização, tanto nas questões objetivas quanto nas subjetivas (FISCHER, 2000).

Um exemplo de questão subjetiva diferenciada nas organizações familiares é o conflito. No caso de organizações familiares este "agrava-se" justamente pela reação da empresa com a família. Silva e Rossetto (2010, p. 42) discorrem que os conflitos da relação família versus organização estão associados a duas categorias: as "situacionais (conflito de papéis) e as demográficas (horas trabalhadas, número de filhos)" que geram distúrbios tanto no núcleo da empresa quanto na família. Por exemplo, conflitos situacionais surgem da relação do papel de "pai" e o de "diretor da empresa" enquanto o demográfico pode estar relacionado ao tempo que um cônjuge disponibiliza para assuntos da empresa e para a família.

Dentro da abordagem aqui adotada, defende-se que as construções sociais transformadoras de uma ferramenta estratégica em uma organizacional familiar vão se relacionar, também, com as demandas familiares inseridas nas categorias situacionais e demográficas. Ou seja, a transformação da ferramenta tente a incluir, em parte, elementos do contexto familiar, assim como inclui elementos de outros contextos, como o organizacional. De maneira recíproca, dentro da lógica da construção social da realidade, é esperado que a transformação da ferramenta também interfira nos contextos que a transformam. Ou seja, as transformações sociais incluem a ferramenta, a organização, e a família de maneira imbricada.

Para confrontar empiricamente as contribuições teóricas articuladas até aqui, será apresentada a seguir uma investigação sobre transformações sociais em uma ferramenta potencialmente estratégica, um software, implantado em uma organização familiar brasileira. Cabe destacar que o termo potencialmente é utilizado aqui para demarcar a diferença entre duas concepções sobre o software em questão: a concepção instrumental deliberada, de que se trata de uma ferramenta estratégica, pois foi implantada, também, para dar suporte ao processo decisório ligado à estratégia organizacional; a concepção da prática, cujo potencial estratégico pode ou não ser reconhecido pelos grupos sociais, e os usos da ferramenta podem ou não ser alinhados com a estratégia organizacional, realizando parcialmente ou não realizando esse potencial. 


\section{ASPECTOS METODOLÓGICOS}

A abordagem aqui adotada é a qualitativa, baseada na fenomenologia social com foco no contexto social (MACEDO; BOAVA; ANTONIALLI, 2012). A escolha por adotar a abordagem da Fenomenologia Social de Alfred Schütz se justificada por seu potencial para tratar da "análise de fenômenos do cotidiano das organizações a partir da perspectiva de quem os vivencia" (VIEIRA; RIVERA, 2012, p. 268).

No contexto fenomenológico, as organizações exprimem fatos sociais, espelhando uma configuração que viabiliza a compreensão de nossas sociedades. Essas sociedades são geradas a partir das "experiências vividas" (BERGER; LUCKMANN, 1985). Essas experiências são socialmente construídas, pois se desenvolvem a partir do conhecimento acumulado, adquirido de outros indivíduos vinculadas as experiências vividas anteriormente (SCHÜTZ, 1967). Por sua vez, ao serem analisadas pelo pesquisador a partir dos dados coletados, elas revelam os fenômenos no cotidiano organizacional (VIEIRA; RIVERA, 2012).

\subsection{COLETA DE DADOS}

Uma técnica de coleta de dados aqui adotada foi a entrevista semiestruturada, baseada em um roteiro e considerada adequada para abordagens Fenomenológicas (MACEDO; BOAVA; ANTONIALLI, 2012). O roteiro de entrevista foi desenvolvido a priori com base no referencial teórico levantado com lastro nos objetivos da pesquisa.

As primeiras entrevistas tiveram como objetivo adicional ser uma etapa de ajuste no roteiro, pois havia a preocupação de fazer uso das interações com os respondentes para identificar ajustes necessários no roteiro. Cabe destacar que o roteiro na entrevista semiestruturada não é um questionário aberto lido pelo pesquisador, como o conjunto de perguntas obrigatórias, definido a priori, adotado nas entrevistas estruturadas. O roteiro é um conjunto de tópicos e questões que norteiam os questionamentos criados pelo pesquisador durante a interação com o respondente e de acordo com o andamento dela, para que não se deixe de lado aspectos relevantes para a pesquisa. Portanto, a referida revisão se deu no sentido de destacar melhor alguns desses aspectos, para facilitar o trabalho do pesquisador ao criar os referidos questionamentos durante as interações.

Outra técnica adotada foi a observação participante, "na qual o observador e os observados encontram-se em uma relação de interação que ocorre no ambiente de trabalho 
dos observados" (ABIB; HOPPEN; HAYASHI JUNIOR, 2013, p. 607). A observação ocorreu durante seis meses, no prédio administrativo da empresa (a sede), que concentra uma das lojas de maior faturamento e o aparato administrativo nos andares superiores. Complementarmente se passou ao menos dois dias em cada loja e no Centro de Distribuição da empresa. Os dados coletados na observação foram descritos em um diário de campo. A terceira técnica adotada foi a pesquisa documental (ALVES-MAZZOTI; GEWANDSZNAJDER, 2000), que teve como foco coletar, basicamente, documentos sobre a história da empresa e dados relacionados com a ferramenta investigada.

Para as entrevistas foram escolhidos como sujeitos: os membros familiares que atuam na organização; e atores inseridos em diferentes níveis hierárquicos da organização diretamente ligados ao uso do software, pois, potencialmente, tendem a apresentar usos distintos do software. Na Figura 1 relacionamos os sujeitos escolhidos para participar das entrevistas. Ocorreu um total de dezessete entrevistas com duração entre uma hora e quarenta a até trinta minutos, registradas por meio de gravador. $\mathrm{O}$ áudio foi transcrito, conjuntamente com as anotações feitas a parte durante as entrevistas.

Figura 1 - Relação de cargos e entrevistados

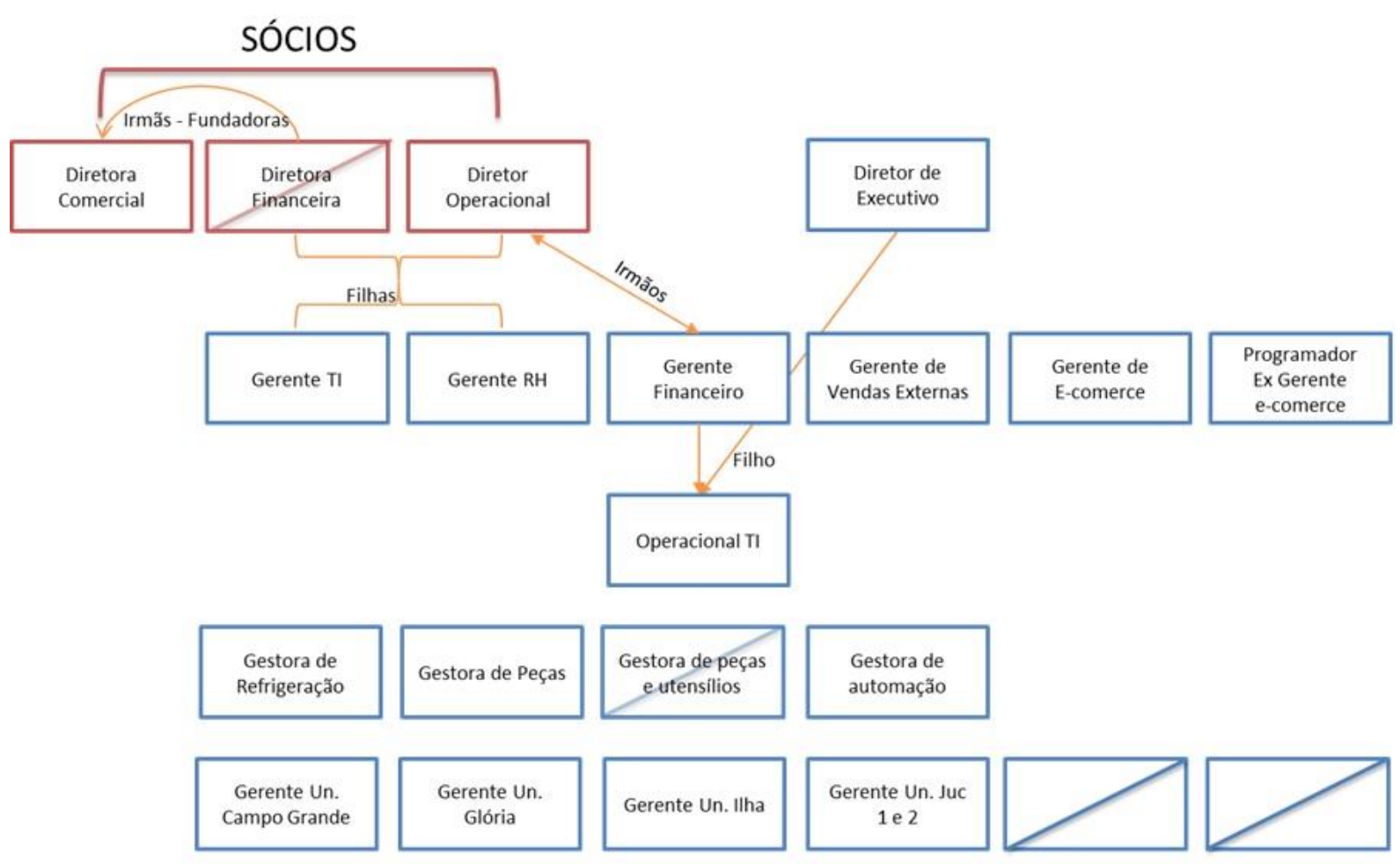

Fonte: elaborada pelos autores. 
Para manter o anonimato, a empresa foi identificada como Alfa e codificamos o nome dos entrevistados em duas partes: na apresentação do contexto por seus cargos; na análise dos dados por meio de nomes fictícios. Procedemos desta forma pois juntando-se os cargos aos nomes, mesmo codificados, as pessoas serão identificadas e há o compromisso do anonimato.

\subsection{O LOCUS E O OBJETO DE ESTUDO}

A Alfa é uma empresa brasileira, situada no estado do Espirito Santo, do setor de Revenda de Peças e Equipamentos, fundada por duas irmãs, em 1988. O marido de uma delas entrou mais tarde na sociedade (o casal possui ao todo 67\% das cotas). Em março de 2005 foi finalizada a instalação do primeiro sistema integrado da empresa, que unia de ponta a ponta a empresa, tanto em relação à frente de lojas (vendas) quanto compras, pagamentos e contabilidade. Em 2008 a Alfa faturou mais de 75 milhões de reais com um total de sete filiais.

Entretanto, apesar do aumento de lojas e centros de resultado, a partir de 2009 as vendas sofreram retração e em 2013 a empresa faturou aproximadamente 45 milhões de reais com nove filiais. Neste mesmo ano foi feito o investimento na ferramenta potencialmente estratégica investigada: um software, denominado nesta pesquisa como o Shiva. O nome fictício foi definido para manter o anonimato da Alfa, pois, ela foi o primeiro cliente, varejista, da empresa distribuidora dele no estado e essa é uma informação pública.

O Shiva é utilizado por todos que trabalham com um computador na empresa. Ele une em uma base WEB as compras para estoque, vendas de balcão nas lojas e e-commerce. Ele pode ser considerado com potencial para ser uma ferramenta estratégica, por reunir num só lugar todas as áreas e informações da organização, com a possibilidade de cruzamento dos dados em relatórios diversos, fomentando a análise estratégica.

\subsection{PROCESSO DE ANÁLISE DOS DADOS}

O procedimento de análise de dados utilizado foi o método de Sanders (1982) que é alinhado à abordagem Fenomenologia Social de Alfred Schütz. A abordagem desse método aqui adotada foi atualizada a partir de contribuições de Macedo, Boava e Antonialli (2012). O processo de coleta de dados e análise dos dados está descrito na Figura 2. 
Figura 2 - Processo de captação e Análise dos Dados

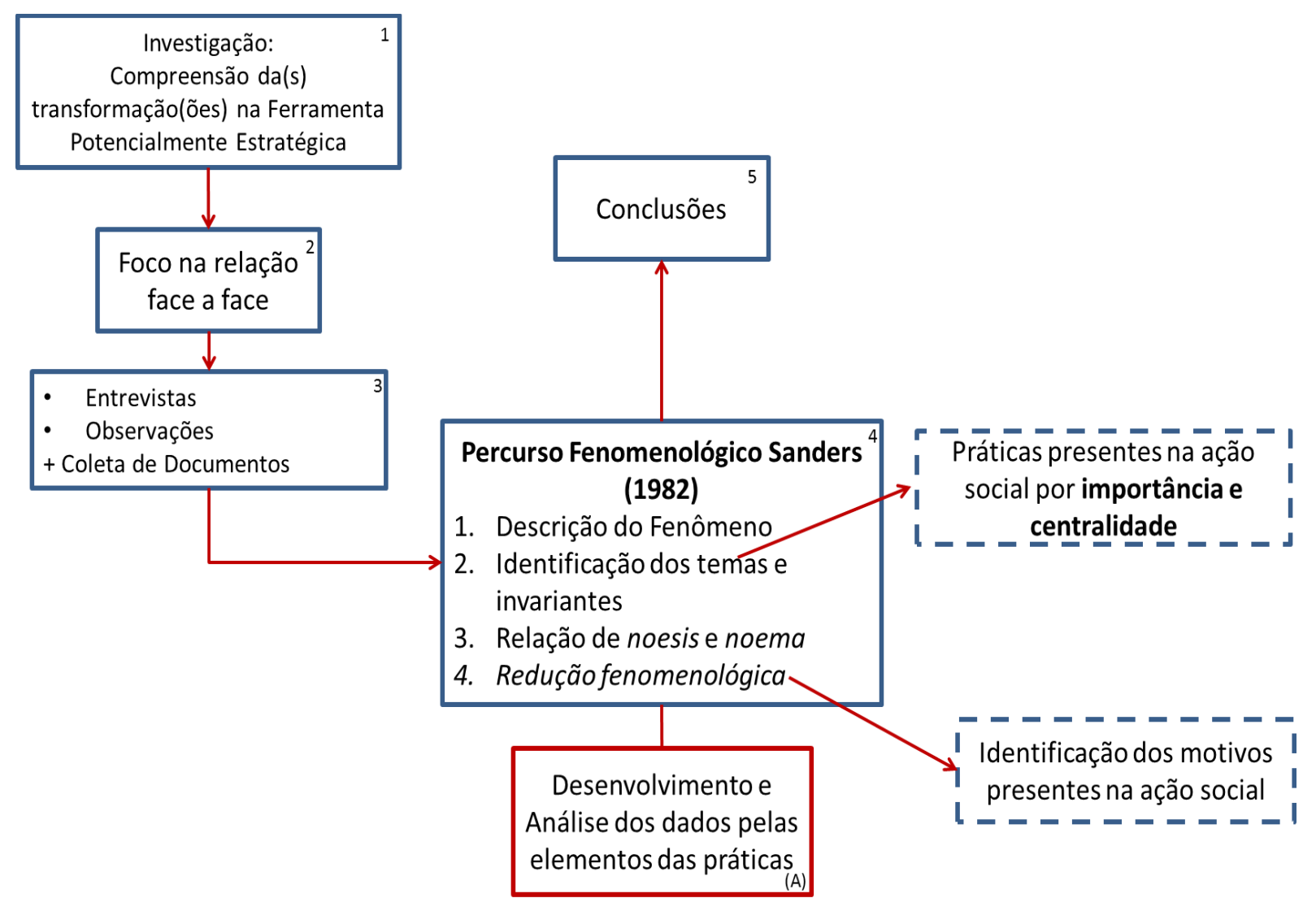

Fonte: elaborada pelos autores a partir de Sanders (1982) e de Macedo, Boava e Antonialli (2012).

\section{A TRANSFORMAÇÃO SOCIAL DA FERRAMENTA}

A primeira etapa da análise fenomenológica de Sanders (1982) é a descrição do fenômeno a partir dos dados coletados. Neste estudo o fenômeno se apresentou como sendo "usos e transformações". No contato com o contexto organizacional, em seu uso, a ferramenta é transformada e novos usos surgem. Por exemplo, uma gerente percebeu que poderia mudar as atividades dos diretores, alegando que o "sistema não permitiria" aquelas atitudes.

A segunda etapa do método de Sanders (1982) é a identificação dos temas e invariantes, aqui ela consistiu na "identificação das práticas", quando foram delineados três grupos: práticas a partir da escolha da ferramenta; práticas no uso da ferramenta; e as práticas transformadoras em ferramenta estratégica. Cada um dessas práticas foi subdividida em unidades de sentido em um total de dez unidades discutidas a seguir. A forma de análise está de acordo com a terceira etapa da abordagem metodológica: o detalhamento de quais são as experiências ("O que" - fator objetivo), como elas se apresentam ("Como" - fator subjetivo) e 
os motivos da transformação que emanam dessas experiências.

\subsection{PRÁTICAS A PARTIR DA ESCOLHA DA FERRAMENTA ESTRATÉGICA}

\subsubsection{Como a ferramenta se apresenta}

Nos dados analisados fica clara a existência de uma grande resistência na aceitação da ferramenta, principalmente nos relatos dos entrevistados com mais de cinco anos de empresa. Isso pode ser percebido em trechos de entrevistas como: "gostaria de jogar o sistema pela janela" (AMANDA); "uma grande 'dor de cabeça" (AUCLIDES); "a migração para ele foi muito traumática" (FABRÍCIA).

Essas incongruências no lidar com tecnologias (MUSSI; ZWICKER, 2012), surgiram também influenciadas pela diferença entre o que esperavam e o que conheceram do sistema. Isso é evidenciado num trecho de entrevista da Célia: "agente esperava muito e foi um tiro no pé. Foi decepcionante, foi triste, foi ruim, ficamos tanto tempo com vários problemas". Como motivos para esse rancor e ressentimento surgiram duas questões centrais: a pressão da própria diretoria em mudar, o mais rápido possível, de sistema; e a falta de treinamento para os membros da organização de forma direcionada.

As pessoas contratadas após a implantação do sistema não tiveram essa experiência em si, mas quando entram em contato com aquele contexto começam a ser capazes de ler as objetivações e subjetivações sobrescritas na ferramenta estratégica, pois ela é um artefato simbólico (DA FONSECA; MACHADO-DA-SILVA, 2010). Mesmo os novos membros passaram a lidar com o "trauma" que a ferramenta carrega no contexto da organização.

Pode-se argumentar que a ferramenta estratégica se apresenta, inicialmente, como um artefato que carrega, pela leitura subjetiva dos indivíduos, as mágoas de um período turbulento da empresa, que foi gerado por problemas objetivos, como falta de treinamento e problemas no sistema, traduzido em uma experiência percebida como despreparo. O Quadro 1 (Subdivisão A) resume essas questões sobre a apresentação da ferramenta.

\subsubsection{Escolha e troca da ferramenta}

Os motivos identificados para a troca da ferramenta foram: a necessidade de uma ferramenta de controle; as necessidades fiscais; e a estagnação ou a falta de manutenção do 
sistema anterior. Segundo Célia, eles estavam "totalmente sem controle, estoque errado, tudo errado, não tínhamos controle", já para Auclides o motivo que os levaram a "trocar o sistema, foi às obrigações que você tem de apresentar os arquivos eletrônicos para o governo" e a estagnação do sistema anterior.

Quadro 1 - Mapa dos Temas Analisados

\begin{tabular}{|c|c|c|c|c|c|}
\hline PRÁTICAS & CARACTERIZAÇÃO & $\begin{array}{c}\text { ELEMENTOS DA } \\
\text { PRÁTICA }\end{array}$ & $\begin{array}{c}\text { Como - } \\
\text { Subjetivo }\end{array}$ & O que - Objetivo & \begin{tabular}{|c|} 
Motivo da \\
transformação
\end{tabular} \\
\hline \multirow[b]{3}{*}{ 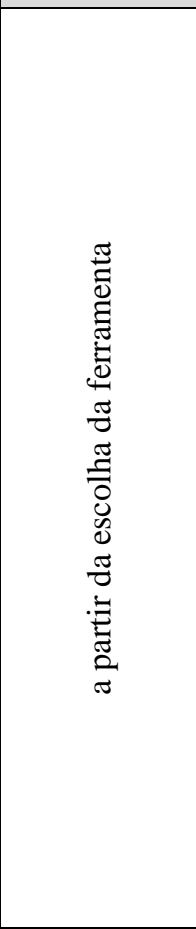 } & \multirow{3}{*}{$\begin{array}{l}\text { Compreende } \\
\text { momento da escolha e } \\
\text { apresentação da } \\
\text { ferramenta, que por sua } \\
\text { vez gera a a } \\
\text { "expectativa" de "como } \\
\text { seria a ferramenta" e a } \\
\text { percepção de como ela } \\
\text { "realmente é" na visão } \\
\text { dos entrevistados, que } \\
\text { emana do contraste da } \\
\text { expectativa com o seu } \\
\text { uso. Isto é o confronto } \\
\text { das percepções de } \\
\text { expectativa e uso com } \\
\text { os sentimentos que os } \\
\text { usuários demonstram } \\
\text { da ferramenta, dá a } \\
\text { possibilidade re de } \\
\text { analisarmos o primeiro } \\
\text { foco da transformação } \\
\text { que foi na escolha da } \\
\text { ferramenta. }\end{array}$} & $\begin{array}{l}\text { A. Como a } \\
\text { Ferramenta se } \\
\text { apresenta }\end{array}$ & $\begin{array}{l}\text { Ressentimento, } \\
\text { rancor e } \\
\text { desconfiança }\end{array}$ & $\begin{array}{l}\text { Problemas na } \\
\text { "virada" do } \\
\text { sistema }\end{array}$ & Despreparo \\
\hline & & $\begin{array}{l}\text { B. Escolha e } \\
\text { troca da } \\
\text { ferramenta }\end{array}$ & $\begin{array}{l}\text { Interesses e } \\
\text { leituras } \\
\text { ambientais }\end{array}$ & $\begin{array}{l}\text { Necessidade de } \\
\text { Mudança }\end{array}$ & $\begin{array}{l}\text { Crescimento } \\
\text { baseado no } \\
\text { feeling }\end{array}$ \\
\hline & & \begin{tabular}{|l} 
C. \\
Expectativas e \\
transformaçõe \\
$\mathrm{s}$
\end{tabular} & $\begin{array}{l}\text { Não } \\
\text { atendimento } \\
\text { das } \\
\text { expectativas }\end{array}$ & $\begin{array}{l}\text { Divergência entre } \\
\text { o "vendido" e } \\
\text { expectativas } \\
\text { socialmente } \\
\text { construídas }\end{array}$ & $\begin{array}{l}\text { Redes de } \\
\text { motivos e } \\
\text { interesses }\end{array}$ \\
\hline \multirow{4}{*}{ 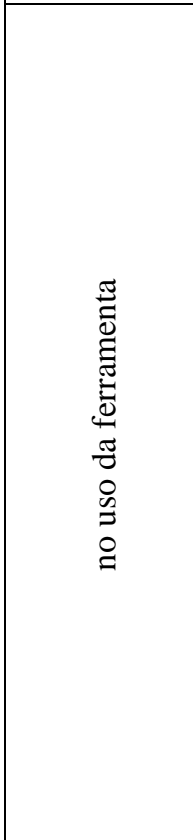 } & \multirow{4}{*}{ 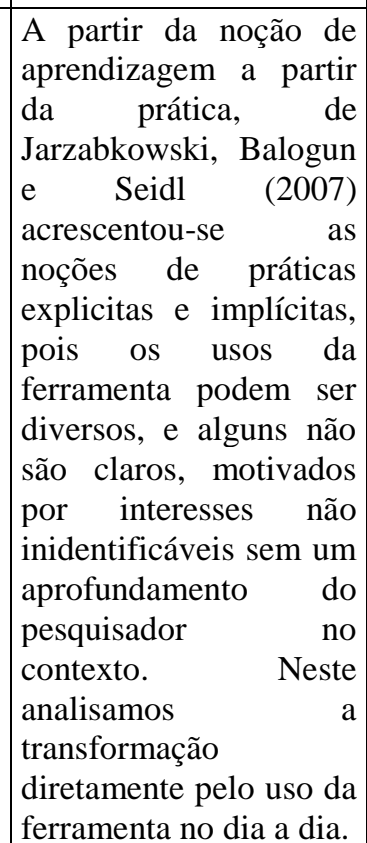 } & $\begin{array}{l}\text { D. Uso Focado } \\
\text { em vendas }\end{array}$ & $\begin{array}{l}\text { "Cultura" dos } \\
\text { sócios/da } \\
\text { empresa }\end{array}$ & $\begin{array}{l}\text { Análise feita } \\
\text { somente por } \\
\text { vendas }\end{array}$ & $\begin{array}{l}\text { Imposição } \\
\text { implícita e } \\
\text { explicita, para } \\
\text { foco em vendas }\end{array}$ \\
\hline & & 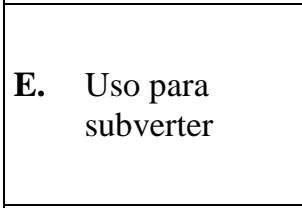 & $\begin{array}{l}\text { Tentativa de } \\
\text { mudança de } \\
\text { nas } \\
\text { construções } \\
\text { sociais } \\
\end{array}$ & $\begin{array}{l}\text { Uso além da } \\
\text { ferramenta }\end{array}$ & $\begin{array}{l}\text { Alcance de } \\
\text { objetivos do } \\
\text { ator social }\end{array}$ \\
\hline & & 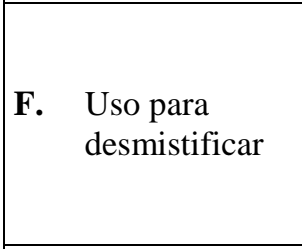 & $\begin{array}{l}\text { Sentimentos de } \\
\text { surpresa, } \\
\text { confusão sobre } \\
\text { algumas } \\
\text { práticas e } \\
\text { discursos } \\
\end{array}$ & $\begin{array}{l}\text { Uso emergente } \\
\text { de validação de } \\
\text { práticas e } \\
\text { discursos }\end{array}$ & $\begin{array}{l}\text { Percepção de } \\
\text { que alguns } \\
\text { discursos e } \\
\text { práticas podem } \\
\text { ser incoerentes } \\
\text { ao contexto } \\
\end{array}$ \\
\hline & & \begin{tabular}{|l} 
G. O "não uso" \\
ou "usar \\
pouco"
\end{tabular} & $\begin{array}{l}\text { Uso } \\
\text { acomodado às } \\
\text { circunstâncias }\end{array}$ & $\begin{array}{l}\text { Uso dissimulado } \\
\text { da ferramenta }\end{array}$ & $\begin{array}{l}\text { Herança do } \\
\text { contexto, } \\
\text { tentativa (d)e } \\
\text { manutenção de } \\
\text { práticas. }\end{array}$ \\
\hline
\end{tabular}


Quadro 1 - Mapa dos Temas Analisados

\begin{tabular}{|c|c|c|c|c|c|}
\hline 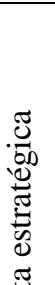 & $\begin{array}{l}\text { A noção de estratégia } \\
\text { foi modificada para } \\
\text { compreender não } \\
\text { somente o que é } \\
\text { estratégico para aquele } \\
\text { grupo, mais também a } \\
\text { transformação do uso }\end{array}$ & $\begin{array}{l}\text { H. Transformação } \\
\text { pela } \\
\text { expectativa }\end{array}$ & $\begin{array}{l}\text { Expectativa do } \\
\text { ator social de } \\
\text { como a } \\
\text { ferramenta } \\
\text { poderá ser } \\
\text { utilizada }\end{array}$ & $\begin{array}{l}\text { Necessidade } \\
\text { estratégica }\end{array}$ & $\begin{array}{l}\text { Experiência de } \\
\text { vida do } \\
\text { indivíduo e } \\
\text { interesses } \\
\text { organizacionais } \\
\text { ou de grupos } \\
\text { sociais }\end{array}$ \\
\hline 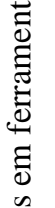 & $\begin{array}{l}\text { do software em si. Isto } \\
\text { é, como as práticas do } \\
\text { ator social levam o } \\
\text { significado de "simples } \\
\text { uso", para r uso }\end{array}$ & $\begin{array}{l}\text { I. Transformação } \\
\text { pela análise }\end{array}$ & $\begin{array}{l}\text { "Vontade" do } \\
\text { ator social em } \\
\text { usar o sistema } \\
\text { de forma } \\
\text { estratégica } \\
\end{array}$ & $\begin{array}{l}\text { Uso de análise } \\
\text { pela ferramenta } \\
\text { para fins } \\
\text { estratégicos }\end{array}$ & $\begin{array}{l}\text { Interesses } \\
\text { organizacionais } \\
\text { e dos atores } \\
\text { sociais }\end{array}$ \\
\hline 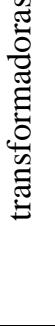 & $\begin{array}{l}\text { estratégico } \\
\text { ferramenta. Esta prática } \\
\text { dá conta então de reunir } \\
\text { as (re)transformações e } \\
\text { a compreensão dos } \\
\text { indivíduos do ro uso } \\
\text { estratégico }\end{array}$ & $\begin{array}{ll}\text { J. Transformação } \\
\text { pelo } \\
\text { treinamento }\end{array}$ & $\begin{array}{l}\text { Necessidade } \\
\text { de treinamento } \\
\text { técnico e de } \\
\text { conhecimentos } \\
\text { que são } \\
\text { permeados por } \\
\text { conflitos }\end{array}$ & $\begin{array}{l}\text { Treinamento } \\
\text { operacional e } \\
\text { educacional } \\
\text { como fomentador } \\
\text { do uso } \\
\text { estratégico }\end{array}$ & $\begin{array}{l}\text { Forma de } \\
\text { dissipar } \\
\text { barreiras do } \\
\text { contexto } \\
\text { social, para } \\
\text { transformação } \\
\text { em ferramenta } \\
\text { estratégica }\end{array}$ \\
\hline
\end{tabular}

Fonte: elaborado pelos autores.

Essa diferença é explicada pelo fato de que a realidade dos indivíduos contribui para a forma que cada um olha para o mundo (GERGEN, 1999). Por exemplo, é possível resgatar eventos pontuais que alteraram o discurso de alguns entrevistados. O que retoma a necessidade do discurso ser analisado conjuntamente com seu contexto (BERGER; LUCKMANN, 1985). Esta situação é exemplificada em três momentos: quando o discurso da Célia foi modificado pela apresentação dos resultados no segundo semestre de 2014; quando o discurso de Auclides foi modificado após ter começado a verificar questões contábeis; e um momento no qual a diretoria identificou a necessidade de deixar de lado as decisões baseadas em feeling e buscou meios para passar a se basear em dados para a estratégia.

Sobre este último, cabe destacar que até 2008 as decisões baseadas no feeling pessoal dos sócios eram vistas como algo positivo, pois a empresa crescia nesse período. A partir de 2009, com a retração de receita isso passou a ser questionado. Milena comenta que "isso nunca foi visto antes, nunca foi trabalhado decisão em base de números nessa empresa, foi tudo sempre governado no emocional".

O forte crescimento baseado no feeling e a posterior retração do faturamento permeiam o reconhecimento de que a empresa necessitava de: melhor controle, entrosamento entre áreas, e a necessidade de uma ferramenta que possibilitasse a análise dos dados da empresa para a tomada de decisão, isto é a análise estratégica dos dados. O Quadro 1 (Subdivisão B) resume estas questões. 
A substituição do feeling pelo uso de uma ferramenta mais profissional de gestão trouxe outras transformações, por exemplo, causou certo afastamento da família de algumas relações de trabalho, isto é, mudou a relação da articulação entre a família e a organização (FISCHER, 2000), pois até então os sócios atuavam “"administrando com o coração', [...] Tipo assim, o funcionário é bom, coisa e tal, vamos segurar porque ele é "bonzinho" é de confiança" (AUCLIDES).

Além das questões relativas à escolha da ferramenta e como a ferramenta se apresenta, há a expectativa de como ela será antes de sua implantação como descrito a seguir.

\subsubsection{Expectativas e Transformações}

O primeiro contato com a ferramenta foi durante a sua escolha. A escolha da ferramenta é permeada pelas construções sociais dos incumbidos em escolhê-la. Estas construções não são compartilhadas por todos, mas geram uma interpretação de como será o uso, a partir da divulgação de como deverá ser a ferramenta.

Nesse sentido consegue-se perceber que existem variedades de expectativas, e percepções das distorções entre o discurso e resultado. Por exemplo, Amanda relembra que disseram que o Shiva "era o melhor, né? Mas, quando foi implantado eu não vi isso, até por conta de todos os problemas de implantação". Por outro lado, existem discursos que apontam o oposto como pode ser evidenciado em: "[o Shiva é] muito melhor, [...] algumas funções que você executava no sistema antigo, ele dava um erro" (LEANDRO). E também: "a mudança foi que nossa dificuldade era para tirar pedido... e hoje está muito mais fácil" (MARCELO).

A partir dessas manifestações argumenta-se que a expectativa sobre a ferramenta estratégica pode ser a ideal para um grupo, mas não necessariamente exprime a interpretação de todos os grupos na organização. Essas expectativas e interpretações parecem ser geradas de forma objetiva por uma construção idealizada do que seria o sistema vendido em contraste com as práticas cotidianas em torno da ferramenta.

Ficou claro que as razões em torno da aquisição e dos usos do software, baseiam-se predominantemente em aspectos subjetivos. Aspectos relacionados ao tipo de uso do sistema antigo, também influenciam essas questões, pois a partir do momento em que se instalou o software se começa a perceber a diferença entre a expectativa, o que está sendo experenciado agora e a experiência com o software anterior. O Quadro 1 (Subdivisão C) resume essas 
análises sobre a expectativa e realidade. A questão do uso é aprofundada na prática a seguir.

\subsection{PRÁTICAS NO USO DA FERRAMENTA}

\subsubsection{Uso focado em vendas}

A primeira forma de prática no uso da ferramenta identificado é o uso desenvolvido de cima para baixo, proposto diretamente pela diretoria, que, como apontou Fabrícia, é "focado nas vendas". Mas no cotidiano, esse uso institucional, composto por práticas, não é só da diretoria da organização, ele é construído pelas pessoas, inseridas em um contexto comum. Isso fica evidente em argumentos que associam a operacionalização das vendas como sendo estratégico. Por exemplo, Célia aponta que a "estratégia é [...] fazer vender, né?". Assim, de acordo com essa percepção, se os vendedores estiverem vendendo estarão cumprindo com sua função estratégica.

Esta percepção de uso focado em vendas se estende até o uso dos próprios diretores, que segundo a Fabrícia "[...] têm mais uma cultura de analisar as vendas, venda, venda, venda, venda, não olham o entorno disso, tipo a inadimplência". Inclusive, as metas e prêmios dos vendedores, as cobranças de resultado dos gestores e gerentes são todos vinculados a faturamento de vendas unicamente.

Podemos dizer que há uma leitura subjetiva, compartilhada, sobre o fator transformador de práticas e da ferramenta que é a construção social sobre a ênfase às vendas. O Quadro 1 (Subdivisão D) organiza estes argumentos sobre o uso focado em vendas.

\subsubsection{Uso para Subverter}

Além dos usos instrumentais deliberados e previstos, a ferramenta foi transformada por alguns atores em um meio para subverter os contextos nos quais estão inseridos. De maneira convergente com o que propõe Hodary (2009), as ferramentas estratégicas podem, na prática, ser utilizadas de formas imprevisíveis. Na Alfa essas mudanças, ou usos imprevisíveis, ocorreram tanto na forma de organização, quanto nas práticas do dia a dia.

Um exemplo disso está ligado a Marilene, que aproveitou a transformação do sistema para realizar uma mudança, consciente, em algumas práticas dos sócios em relação à forma de formalização de documentos. Vale ressaltar, que essa uma transformação do uso da 
ferramenta, pois ela não havia sido pensada para isso. Segundo Marilene, antes da mudança do sistema, os sócios pediam ao financeiro para pagar contas pessoais, ou faziam retiras do caixa sem documentos, o que dificultava o controle do caixa. Assim, com a mudança do sistema, ela falou com os diretores que: "Ó o sistema mudou, [...] ]eu não posso fazer dessa maneira, vamos mudar? Vamos? Não posso tirar [retirada do caixa] sem documento". Marilene comentou, durante uma observação, que quando os diretores vinham pedir dinheiro sem um documento, ela negava, dizendo que ia dar problema no fechamento do sistema e na contabilidade.

A partir dos argumentos aqui identificados, consegue-se discutir que objetivamente há uma transformação no uso da ferramenta para além dela, no sentido de ser utilizada para mudar, forçar mudanças ou ainda submeter um conjunto de indivíduos à vontade de quem usa o sistema. Estas questões podem ser explicadas a partir da percepção de que os atores sociais, lançam mão da ferramenta como forma de articular interesses e objetivos diversos, alinhados ou não com os da organização. O Quadro 1 (Subdivisão E) resume essas questões sobre o uso para subverter. Em relação aos objetivos pessoais, além do uso direto para "forçar" mudanças, há outro aspecto, que será abordado a seguir que é o de usar a ferramenta para desmentir ou desmistificar alguns argumentos ou atitudes dentro da Alfa.

\subsubsection{Uso para desmentir ou desmistificar}

Na Alfa a ferramenta é utilizada também para desmentir ou desmistificar discursos na organização. Partindo dos argumentos de Fernandes e Zanelli (2006), o tipo de uso aqui descrito poderá ser visto pelo contraste das duas vertentes, do controle que a instituição possui para buscar impor valores e normas e os padrões reais que surgem da interação e do comportamento das pessoas envolvidas naquele contexto.

O primeiro assunto que se enquadra nesses termos é a questão das vendas para contribuintes ou isentos. Essa nomenclatura serve para diferenciar pessoas físicas e ou jurídicas que são passíveis de recolhimento imposto. Quando o comprador é do tipo contribuinte, é ele quem deverá arcar com o imposto. Já os isentos, como o próprio nome já indica, seria a Alfa a recolher o imposto. Sobre isso Luciana comentou que os vendedores falavam que estavam vendendo principalmente para contribuintes, mas pelo relatório no sistema ela viu que "nem $50 \%$ das minhas vendas estavam sendo para contribuinte como estavam falando para mim que estavam". 
Do relato é possível perceber que, a partir de uma informação dada pelo sistema novo, se desmente o argumento dos vendedores de que eles estão vendendo para contribuintes. Isto é, o sistema se mostrou como um meio para trazer a tona especulações e pontos de vista de dentro da organização (KAPLAN; JARZABKOWSKI, 2006). Esse é um uso que não havia sido previsto antes ficando clara a existência de usos esperados e aqueles que emergem, os que são postos em práticas, tido como "uso real" (FERNANDES; ZANELLI, 2006). O Quadro 1 (Subdivisão F), resume as questões apresentadas sobre o uso para desmentir ou desmistificar. Há também construções que tentam justificar o não uso, ou pouco uso do sistema, que serão discutidas a seguir.

\subsubsection{Uso pela inércia e o usar pouco}

Nesta seção discute-se a tendência a não usar, ou usar o mínimo possível a ferramenta. As entrevistas e observações revelaram que são os sócios os que menos usam o sistema. Esse fato, em primeira instância, vai contra os achados de Jarzabkowski e Giulietti (2007) e Jarzabkowski e Kaplan (2014), uma vez que não há uma tendência de uso da ferramenta pelos "altos gestores".

Essa conclusão de que os sócios não usam a ferramenta é algo compartilhado entre os diretores, e entre alguns funcionários mais próximos a eles. Segundo a Milena, os diretores "não têm habilidade para informática e não estão dispostos a aprender". De acordo com os relatos, essa indisposição para aprender pode estar ligada a uma prática mais antiga, não necessariamente ligada ao Software novo. Eles já estavam habituados a requisitar aos outros as informações que precisam como fica claro nas falas: "[...] pois eu meio que faço tudo para eles. Entrego relatório por e-mail uma coisa que eles mesmos poderiam ir lá e abrir" (MILENA). E, “dos diretores só quem usa bastante a ferramenta é o [Diretor Executivo], os outros pedem as informações e agente entrega na mão. Usam pouco" (MARILENE).

Essas questões não ficam isoladas na diretoria, elas também surgiram em outros níveis hierárquicos, mas de maneira distinta. Os membros organizacionais nos demais níveis esperavam que o próprio sistema daria as diretrizes de trabalho deles próprios, como pode ser visto no recorte da entrevista: "a gente achou que tinha comprado um software pronto para 'sentar' [mas] não; tive que colocar no sistema o que eu precisava" (MARILENE).

A partir deste recorte, pode-se dizer que a inércia de uso construído socialmente fomentou uma expectava de que o sistema também seria compatível com a prática da 
dependência dos usuários em gerarem informações. Ou seja, é quase como se esperassem que o sistema sozinho entendesse o trabalho deles, definisse a informação que eles precisam e encaminhasse as informações a eles. Essa expectativa pode ser explicada pela dificuldade dos usuários em transformar dados em informações, por meio de relatórios e gráficos no software antigo.

Aparentemente, na prática cotidiana, o sistema antigo serviu como artefato associado simbolicamente à ferramenta nova e que carrega conhecimentos compartilhados e linguagem, que, por sua vez, foram repassados à fermenta nova (SPEE; JARZABKIWSKI, 2009). O Quadro 1 (Subdivisão G) apresenta o resumo da discussão aqui apresentada sobre as limitações de uso da ferramenta. Para concluir os temas de análise, a seguir apresentar-se-á os aspectos que levam a transformação do software em ferramenta estratégica.

\subsection{PRÁTICAS TRANSFORMADORAS EM FERRAMENTA ESTRATÉGICA}

\subsubsection{Transformação pela expectativa}

Conforme apresentado anteriormente, a primeira transformação apreendida do contexto é a expectativa de uso, que embora possa produzir usos não estratégicos, os quais já foram apresentados, também pode trazer usos estratégicos. Este argumento fica mais claro pelo contraste de dois recortes de entrevistas: "[...] a gente achou que tinha comprado um software pronto para 'sentar' e que ele viesse nos dar tudo que agente tava precisando" (MARILENE); "ele fornece as informações, mas, você tem que saber fazer as perguntas. Se você não souber o que você quer ele não faz nada" (FABRÍCIA).

A expectativa da Marilene era a de que ele seria algo pronto, cujos cruzamentos e análises, até certo pondo já estivessem previamente disponíveis. Por outro lado, Fabrícia, já argumenta que o sistema oferece novas possibilidades, porém o usuário tem que saber do que precisa, ou formular hipóteses de quais questões seriam pertinentes para que o sistema possa ser configurado para gerar essas informações necessárias. Infere-se então que é necessário um pensamento estratégico, para que o uso da ferramenta possa ser estratégico.

Logo, pode-se argumentar que o fenômeno da transformação da ferramenta em estratégica surge a partir de uma expectativa de como ela poderá ser utilizada para fomentar a estratégia, sendo que, objetivamente, o usuário deve possuir conhecimentos prévios para poder desenvolver a necessidade de um uso estratégico. Deve haver uma necessidade ou 
interesse particular em usá-lo dessa forma, uma razão (SPEE; JARZABKOWSKI, 2009; BELMONDO; SARGIS-ROUSSEL, 2015).

Vale ressaltar que o uso, por uma razão ou interesse, está ligado a duas práticas estratégicas. A estratégia para alcançar o objetivo da empresa e as diretamente ligadas a interesses do ator social (TURETA; LIMA, 2011). Nesse sentido, para o contexto estudado, mostrou-se relevante a questão da escolaridade (JARZABKOWSKI; GIULIETTI, 2007), uma vez que há evidências de que quanto maior o nível de escolaridade mais frequente é o uso da ferramenta como estratégica. O Quadro 1 (Subdivisão H) apresenta o resumo da análise sobre a transformação pela expectativa. A seguir apresentamos as transformações da ferramenta em algo estratégico pela necessidade de se analisar estrategicamente as informações.

\subsubsection{Transformação pela análise}

Para que as decisões possam ser tomadas, os atores sociais deveriam compreender sua necessidade estratégica, e em parte se desvincular da "construção social do foco em vendas" para tomar decisões em outras direções. Estas decisões serviriam para usar a ferramenta como uma base que permita, entre outros, desenvolver a forma de aplicação de recursos disponíveis ou verificar situações favoráveis, ou desfavoráveis para, a partir do cruzamento de informações e análise, chegar a um objetivo comum (MACEDO; BOAVA; ANTONIALLI, 2012). Assim, para que a ferramenta seja tratada como estratégica os dados devem ser transformados em informações e estes devem ser analisados dentro de parâmetros alinhados com as estratégias de cada área que usa o software e da empresa como um todo, entretanto, na Alfa, há evidência de que isso não ocorre na empresa como um todo.

O recorte de entrevista a seguir aponta esta questão: "se você não analisar você não vai a lugar nenhum [...] uns só utilizam essa ferramenta que é o [Shiva], simplesmente para fazer uma transferência, fazendo operação, eles não analisam" (AMANDA). Por outro lado, como pode ser observado no segmento da entrevista a seguir, que em parte da Alfa o Shiva já é usado como ferramenta estratégica: "a partir do sistema, pois pudemos ver 'a [Alfa] está assim' ai conseguimos fazer um planejamento para 2020. [...] não é só 'trocar o sistema'é ter informações para você tomar uma decisão antes [...] as coisas eram tomadas muito no feeling (MILENA).

O uso do Shiva para análise de informações para a tomada de decisões, também levou a vários usos que se enquadram como uso estratégico. Por exemplo, usar a ferramenta para 
encontrar oportunidades de mercado, este argumento pode ser visto no seguinte relato: "nós descobrimos através da análise de alguns relatórios de vendas que a gente pode usufruir de um determinado benefício de um grupo de produtos [... o Shiva] é um aliado na minha tomada de decisão" (MILENA). Esse entendimento vai ao encontro dos argumentos de Wrigth, Paroutis e Blettner (2013) de que as ferramentas estratégias vão além de organizar os dados e pensamentos, servem também para gerar conexões e interconexões com diferentes tipos de informações.

No tocante à interpretação é unanime o entendimento de que o Shiva pode ser uma ferramenta estratégica para a empresa, mas, de maneira ambígua, nem todos reconhecem esse potencial para a sua área de atuação específica. O motivo que perpassa essas compreensões se mostra como a compatibilidade dos interesses organizacionais, com os interesses e motivos do ator social, que o levam a usar, ou não, o sistema de forma estratégica. O Quadro 1 (Subdivisão I) retoma estas questões de maneira resumida sobre a transformação pela análise. Um elemento sempre presente nas entrevistas é a questão do treinamento, e que também se demonstra como fator que também pode levar às transformações na ferramenta. A seguir está a análise de como o treinamento pode ou transforma a ferramenta.

\subsubsection{Transformação pelo treinamento}

Há consenso entre os atores na empresa de que a falta de treinamento do sistema atrapalha seu uso. Nos recortes de entrevista a seguir essa questão e suas consequências estão claras: "Eu acho que hoje a gente não está preparado para ele. Entendeu? Porque não adianta você ter o melhor carro na garagem e não saber dirigir ele" (LUCIANA); "Hoje o pouco que eu tenho, [é] como se eu tivesse uma Ferrari e eu estou usando ela como um gol, mas mesmo assim ela é muito importante para mim" (ISALTINO); "[o Shiva] é uma ferramenta ótima de análise [...], contudo, é o que eu te falei, não adianta você ter uma Ferrari e não saber pilotar, e às vezes a culpa não está em você não saber, não te ensinaram a pilotar" (WESLEY).

Se fossem treinados os atores poderiam fazer usos mais avançados da ferramenta. Isto transformaria seu uso e consequentemente transforma as construções sociais que estabelecem o que é a ferramenta. Alinhado com essa compreensão, quando questionado se ele gostaria que os vendedores fossem treinados para usar a ferramenta para além do básico operacional Jeferson respondeu pontualmente: "Sim, com certeza". Entretanto, em seguida, quando 
perguntado se os vendedores possuíam ou não a vontade de serem treinados para fazer outros usos, respondeu que: "Não. Eu vejo, pois quanto mais eu me aprofundar melhor, agora, para eles [os vendedores] eu acho que não têm interesse" (JEFERSON).

Esse trecho da entrevista leva à reflexão de que, além de serem treinados para usar o sistema, deve haver também acordos sobre os interesses socialmente construídos, suas motivações, para fazer usos estratégicos do sistema e de uma forma consciente. Tendo estas questões em mente, além de um treinamento sobre como a ferramenta pode ser utilizada, há também a necessidade de que os atores sociais construam interesses relacionados com a aplicação dos conhecimentos gerados nesse treinamento. É evidente que não se pode pensar em um vendedor fazendo exatamente o mesmo uso da ferramenta que um diretor, mas a observação realizada indica a existência de contribuições potenciais da ferramenta específicas, para cada área, que não são aproveitadas.

Destes argumentos se consegue propor então que a transformação em ferramenta estratégica também envolve transformações relacionadas com o treinamento. Essas por sua vez, possuem duas vertentes: a operacional do uso objetivo da ferramenta; e o treinamento que passa pelo compartilhamento de experiências dentro da organização e de fora dela o que inclui as experiências de vida, a formação educacional e profissional dos atores. O Quadro 1 (Subdivisão J) resume as questões aqui levantadas sobre a transformação pelo treinamento.

A discussão desenvolvida até aqui indica que essa transformação, além de se relacionar com as práticas transformadoras em ferramenta estratégica, e suas subdivisões, tratadas neste tópico, também se relaciona com os temas "A escolha e as expectativas" e "O uso". Para esclarecer essa relação comum, a seguir, apresentaremos uma análise integrada dos temas.

\subsection{AS TRANSFORMAÇÕES DA FERRAMENTA ESTRATÉGICA E AS RELAÇÕES NO CONTEXTO SOCIAL}

As articulações teóricas defendidas neste trabalho sustentam o entendimento de que as organizações são conjuntos de atores sociais que constroem uma instituição social. O reconhecimento desse processo como algo contínuo dentro de uma organização, no caso da investigação da Alfa, é convergente com as evidências de que o fenômeno da transformação da ferramenta tem início antes mesmo do uso da ferramenta estratégica. Foi possível delinear que a partir de sua escolha já houve o desenvolvimento de práticas que levaram a 
transformação pelos atores sociais que a escolheram.

Em meio a essas transformações de uso foi possível identificar que os contextos sociais dos atores transformam a ferramenta, que por sua vez transformam as construções sociais. Essa inter-relação envolve as redes de interação dos atores, mudanças de papéis e percepções, acúmulo de informações, interesses, o próprio sistema antigo, e experiências de vida dos sujeitos sociais, paralelos à ferramenta, ou externos à organização que também têm sua parcela de participação na construção social.

Em se tratando da transformação em ferramenta estratégica a vontade no sujeito ou grupo social em desenvolver a análise estratégica usando a ferramenta, ou a falta dessa vontade, surgiram como elementos básicos de uma transformação na direção de ser estratégica ou operacional, respectivamente. Mas o desenvolvimento da "vontade" que inclui a "quebra do foco em vendas" não é algo individual, ele perpassa diversas questões, tais como, as construções sociais da família e dos sócios, e o treinamento dos atores.

Em se tratando da abordagem fenomenológica, chega-se à conclusão de que o motivo que permeia o fenômeno das transformações da ferramenta neste contexto emana como causado pelas redes de motivos e interesses, tanto institucionais quanto específicas dos atores sociais, imersos em construções sociais do contexto anterior à mudança da ferramenta e do contexto posterior â mudança, marcado pelo despreparo na aplicação da ferramenta.

\section{CONSIDERAÇÕES FINAIS}

Este estudo se voltou para o seguinte objetivo: compreender o fenômeno da transformação de um software, com potencial para ser uma ferramenta estratégica, pelas construções sociais dos atores inseridos em uma organização familiar brasileira. Ao partir desse objetivo foi possível evidenciar uma transformação da ferramenta em torno das práticas a partir da escolha da ferramenta, das práticas no uso da ferramenta e das práticas transformadoras do software em ferramenta estratégica. Essas práticas se destacaram por sua importância e centralidade, sendo então subdividas em dez unidades de sentido que permitiram chegar a motivos presentes na prática social dos atores da Alfa.

Foi possível concluir que as transformações da ferramenta começaram com sua escolha e foram causadas pelas redes de motivos e interesses, tanto institucionais quanto específicos dos atores sociais, imersos em múltiplas construções sociais. Isto é, não só a ferramenta se transforma, mas também que o próprio contexto apresentou mudanças a partir 
do contato com a ferramenta.

As transformações sociais do software se relacionam com seis grupos de usos que se relacionam com o software atual e com o software que ele substituiu: o não uso ou usar pouco; o uso para desmistificar; o uso para subverter; o uso Focado em vendas; o uso estratégico e o uso operacional. Esses seis grupos abarcam, basicamente, três tipos de práticas: as práticas dos atores sociais que surgiram transformando a ferramenta; as práticas que foram transformadas pela nova composição do contexto social; as práticas que foram descartadas ou desmistificadas por conta da ferramenta estratégica.

Além das relações de uso, foi possível compreender as transformações da ferramenta em duas instâncias. A primeira instância se volta para as interações dos grupos sociais com a ferramenta durante os seguintes momentos: sua escolha, a apresentação para os grupos sociais da Alfa, a criação de expectativas a partir de sua apresentação, e o seu contraste das expectativas dos atores sociais com seu uso. Já a segunda instância se relaciona com a transformação do software em uma ferramenta estratégica a partir de dois aspectos básicos: a expectativa de ocorrer um treinamento que permita a conciliação de conhecimentos; e a prática de parte dos atores voltadas à análise das informações da ferramenta estratégica.

Esses achados vão na direção da motivação para a execução desta pesquisa pois contribuem para preencher lacunas no conhecimento sobre a temática em tela. Isso fica evidente ao se confrontar os argumentos dos autores aqui discutidos frente aos achados empíricos em torno de duas contribuições teóricas.

A primeira se refere à importância de se estudar as ferramentas estratégicas considerando seus contextos (JARRATT; STILES; 2010). Nesta pesquisa evidenciou-se que a compreensão do fenômeno se perderia ao estudar a aplicação da ferramenta fora de seu contexto, pois se percebe que há tantos usos da ferramenta transformados pelo contexto, quanto transformações da ferramenta no próprio contexto causadas por suas interações. Então, analisar a aplicação da ferramenta fora do seu contexto socialmente construído impossibilitaria resgatar e compreender os motivos e relacionamentos que envolvem a transformação e o uso da ferramenta.

A segunda diz respeito ao entendimento de Hansen (2011), que descreve a escolha das ferramentas como influenciadas por questões do contexto (interno) e ambiente (externo). Com base no que foi aqui apresentado expandimos esse entendimento para a compreensão de que a escolha pautada pelas construções sociais de quem seleciona a ferramenta será mediada pelos interesses do ator ou grupos sociais que a escolhem, articuladas na relação entre contextos 
internos (acordos, conflitos e imposições institucionais) e contextos externos (ambiente - a família, concorrentes e fornecedores). Ou seja, evidenciamos razões específicas, socialmente construídas, para a práticas da escolha da ferramenta (JARZABKOWSKI et al., 2013).

Ao oferecer esses entendimentos este estudo contribui para a compreensão da forma pela a qual as ferramentas estratégicas são transformadas. Algo ainda pouco compreendido (GUNN; WILLIAMS, 2007; SPEE; JARZABKOWSKI, 2009; BELMONDO; SARGISROUSSEL, 2015).

Os resultados levantados também podem ser utilizados pelos praticantes para se relacionarem com o contexto de uso de ferramentas estratégicas, pois indica formas de se contornar "problemas" encontrados. Por exemplo, organizar um treinamento vinculado ao uso estratégico do sistema que trará um novo potencial de uso para a ferramenta. Entretanto, cabe reconhecer que, neste artigo, as contribuições se atém a alternativas voltadas para a manutenção do status quo da organização (BOAVA; MACÊDO. 2011) ou para obter resultados imediatos sem uma profunda reflexão (VIEIRA; RIVERA, 2012) sobre os efeitos da ferramenta na organização. Não avançamos sobre essas contribuições uma vez que foge ao escopo proposto para esta pesquisa.

Vale ressaltar, que por se tratar de uma pesquisa de abordagem qualitativa interpretativista, os resultados aqui apresentados não podem ser generalizados. Muito embora ainda possam servir de pistas para outras pesquisas. Dentre essas possibilidades de pesquisas futuras cabe destacar o potencial produzido por uma mudança aparentemente óbvia a entrada do novo software trouxe novas formas dos sócios interagirem com o contexto, principalmente no tocante à mudança da administração pelo feeling (emocional) para uma base de análise pautada em números (racional). Essa mudança é aparentemente óbvia no contexto organizacional, uma vez que a ferramenta foi implantada, também, para que isso pudesse ser realizado.

Entretanto, na prática, ela se depara com um obstáculo a resistência dos próprios sócios, legitimados em sua atuação pela lógica familiar da organização, o que envolve transformações resistências e conflitos com implicações para a própria família empresária. Portanto, como sugestão para estudos futuros revela-se pertinente identificar e compreender possíveis transformações nas práticas da família (sócios e sucessores), a partir das transformações de uma ferramenta no contexto de uma organização familiar, em relação ao planejamento dos problemas familiares (WARD, 1988), uma vez que há a articulação entre a família e a organização (FISCHER, 2000). 
Por fim, cabe destacar que para oferecer essas contribuições este estudo assumiu como limitação principal o reduzido volume de práticas analisadas, pois foi inviável avaliar um número maior de práticas por suas complexidades, variabilidades e quantidades. A partir dessa constatação optou-se por assumir essa limitação para oferecer um aprofundamento maior em um menor número de práticas, o que viabilizou a realização do estudo e as contribuições apresentadas, mesmo que limitadas a um escopo de um menor número de práticas.

\section{REFERÊNCIAS}

ABIB, G.; HOPPEN, N.; HAYASHI JUNIOR, P. Observação participante em estudos de administração da informação no Brasil. Revista de Administração de Empresas, São Paulo, v. 53, n. 6, p. 604-616, 2013.

ANDREWS, T. What is social constructionism? Grounded Theory Review, Mill Valley, v. 11, n. 1, p. 39-46, 2012.

BELMONDO, C.; SARGIS-ROUSSEL, C. Negotiating language, meaning and intention: strategy infrastructure as the outcome of using a strategy tool through transforming strategy objects. British Journal of Management, London, v. 26, n. 1, p. 90-104, 2015.

BERGER, P.; L. LUCKMANN, T. A construção social da realidade: tratado de sociologia do conhecimento. 9. ed. Rio de Janeiro: Vozes, 1985.

BISPO, M. Estudos baseados em prática: conceitos, história e perspectivas. Revista

Interdisciplinar de Gestão Social, Salvador, v. 2, n. 1, p. 13-21, 2013.

BURR, V. Social constructionism. 3. ed. London: Routledge, 2003.

DA FONSECA, V. S.; MACHADO-DA-SILVA, C. L. Conversação entre abordagens da estratégia em organizações: escolha estratégica, cognição e instituição. Revista de

Administração Contemporânea, Curitiba, v. 14, n. esp., p. 51-75, 2010.

FERNANDES, K. R.; ZANELLI, J. C. O processo de construção e reconstrução das identidades dos indivíduos nas organizações. Revista de Administração Contemporânea, Curitiba, v. 10, n. 1, p. 55-72, 2006.

FISCHER, T.; DANTAS, M.; DAVEL, E. Organizações familiares como linha de pesquisa.

Organizações \& Sociedade, Salvador, v. 7, n. 18, p. 43-44, 2000.

GERGEN, K. J. An invitation to social construction. London: Sage, 1999.

GILL, M. J. The possibilities of phenomenology for organizational research. Organizational 
Research Methods, Thousand Oaks, v. 17, n. 2, p. 118-137, 2014.

GUNN, R.; WILLIAMS, W. Strategic tools: an empirical investigation into strategy in practice in the UK. Strategic Change, Hoboken, v. 16, n. 5, p. 201-216, 2007.

HODARY, D. Strategy tools-in-practice: contextual factors and practical use. 2009. $306 \mathrm{f}$. Tese (Doutorado em Filosofia) - School of Management, University of Surrey, Guildford, 2009.

JARRATT, D; STILES D. How are methodologies and tools framing managers strategizing practice in competitive strategy development? British Journal of Management, London, v. 21, n. 1, p. 28-43, 2010.

JARZABKOWSKI, P.; BALOGUN, J.; SEIDL, D. Strategizing: the challenges of a practice perspective. Human Relations, London, v. 60, n. 1, p. 5-27, 2007.

JARZABKOWSKI, P.; GIULIETTI, M. Strategic management as an applied science: but not as we (academics) know it. In: The Third Organization Studies Summer Workshop, 3., 2007, Creta. Anais eletrônicos... Disponível em: < https://mafiadoc.com/strategic-management-asan-applied-science-but-not-as-we-_59985a4c1723dd95bd2a74fc.html >. Acesso em: 27 out. 2017.

JARZABKOWSKI, P.; GIULIETTI, M.; OLIVEIRA, B.; AMOO, N. We don't need no education - or do we? Management education and alumni adoption of strategy tools. Journal of Management Inquiry, Thousand Oaks, v. 22, n. 1, p. 452-472, 2013.

JARZABKOWSKI, P.; KAPLAN, S. Strategy tools-in-use: a framework for understanding "technologies of rationality" in practice. Strategic Management Journal, Hoboken, v. 36, n. 4, p. 537-558, 2015.

KAPLAN, S.; JARZABKOWSKI, P. Using strategy tools in practice: how tools mediate strategizing and organizing. AIM Research Paper, [s.1.], v. 1, n. 47, p. 1-57, 2006.

Disponível em: < https://papers.ssrn.com/sol3/papers.cfm?abstract_id=1309556 >. Acesso em: 27 out. 2017.

MACEDO, F. M. F.; BOAVA, D. L. T.; ANTONIALLI, L. M. A fenomenologia social na pesquisa em estratégia. Revista de Administração de Mackenzie, São Paulo, v. 13, n. 5, p. 171-203, 2012.

SANCHIS, J. R. P.; CAMPOS, V. C.; MOHEDANO, A. S. Management in social enterprises: the influence of the use of strategic tools in business performance. International Entrepreneurship and Management Journal, v. 9, n. 4, p. 541-555, 2013.

SANDERS, P. Phenomenology: a new way of viewing organizational research. Academy of 
Management Review, New York, v. 7, n. 3, p. 353-360, 1982.

SANTIAGO, A. L. The family in family business case of the in-laws in Philippine businesses. Family Business Review, Vermont, v. 24, n. 4, p. 343-361, 2011.

SCHÜTZ, A. The phenomenology of the social world. Evanston: Northwestern University Press, 1967.

SCHWANDT, T. A. Three epistemological stances for qualitative inquiry: interpretavism, hermeneutics, and social constructionism. In: DENZIN, N. K.; LINCOLN, Y. S. (Eds.).

Handbook of Qualitative Research. 2. ed. Thousand Oaks: Sage, 2000. p. 189-213. SILVA JUNIOR, A.; MARTINS-SILVA, P. O.; SILVA, A. R. L. da. Sistema de valores e implicações na governança corporativa em um grupo empresarial familiar. Organizações \& Sociedade, Salvador, v. 20, n. 65, p. 239-260, 2013.

DA SILVA, A. B.; ROSSETTO, C. R. Os conflitos entre a prática gerencial e as relações em família: uma abordagem complexa e multidimensional. Revista de Administração Contemporânea, Curitiba, v. 14, n. 1, p. 40-60, 2010.

SPEE, A. P.; JARZABKOWSKI, P. Strategy tools as boundary objects, Strategic

Organization, London, v. 7, n. 2, p. 223-232, 2009.

TURETA, C.; LIMA, J. B. Estratégia como prática social: o estrategizar em uma rede interorganizacional. Revista de Administração Mackenzie, São Paulo, v. 12, n. 6, p. 76-108, 2011.

VIEIRA, A. M.; RIVERA, D. P. B. A Hermenêutica no campo organizacional: duas possibilidades interpretativistas de pesquisa. Revista Brasileira de Gestão de Negócios, São Paulo, v. 14. n. 44, p. 261-273, 2012.

VOGEL, R. The visible colleges of management and organization studies: a bibliometric analysis of academic journals. Organization Studies, London, v. 8, n. 33, p. 1015-1043, 2012.

WARD, J. L. The special role of strategic planning for family business. Family Business Review, Vermont, v. 1, n. 2, p. 105-117, 1988. 